\title{
Studies towards the total synthesis of novel marine diterpene havellockate. Construction of the tetracyclic core
}

\author{
Goverdhan Mehta* and R. Senthil Kumaran \\ Department of Organic Chemistry, Indian Institute of Science, Bangalore 560 012, India
}

\begin{abstract}
The synthesis of the tetracyclic core present in the novel marine diterpenoid havellockate $\mathbf{1}$ has been accomplished from the readily available endo-dicyclopentadienone-10-ethylene ketal $\mathbf{3}$ as a prelude to the projected total synthesis of the natural product.
\end{abstract}

Diterpenes in general and particularly those of marine origin are rich in skeletal diversity and structural complexity and many of them possess impressive and wide ranging biological activities. ${ }^{1}$ These attributes make diterpenenoids from marine sources attractive and challenging targets of synthesis. ${ }^{1}$ In 1998, a new diterpenoid named havellockate 1, bearing a novel skeleton, was isolated from the soft coral species Sinularia granosa collected from the Havellock island of the Andaman and Nicobar group of Islands in the Indian ocean. ${ }^{2}$ The structure of havellockate 1 was determined on the basis of spectral data and confirmed by single-crystal X-ray analysis. ${ }^{2}$ The skeleton of $\mathbf{1}$ is biogenetically quite intriguing and is probably derived from a cembranoid precursor through extensive restructuring and concomitant oxy-functionalization. The tetracyclic core present in the complex structure of $\mathbf{1}$ with eight stereogenic centers and many functionalities consists of a cis-fused hydrindane moiety to which two $\gamma$-lactone units are appended, one of them being spiro-fused. These structural features of $\mathbf{1}$ aroused our interest in its total synthesis. As the first objective, we targeted the tetracyclic core structure $\mathbf{2}$, identified through retrosynthetic considerations indicated in Scheme 1. It was surmized that with the acquisition of the tetracyclic ketolactone 2, the overall strategy could be tactically modified and adopted for the synthesis of $\mathbf{1}$. Herein, we report a synthesis of tetracyclic ketolactone $\mathbf{2}$ with complete regio- and stereocontrol.

For the synthesis of $\mathbf{2}$, readily available ${ }^{3}$ endo-dicyclopentadienone 3 was chosen as the starting material as the cis-hydrindane moiety is embedded into this framework (see bold portion in 3) and can be unravelled by removing the ketal bearing $\mathrm{C}-10$ carbon bridge. ${ }^{4}$ Stereoselective epoxidation of the enone moiety in $\mathbf{3}$ to exo-epoxide $\mathbf{4}$ and hydride reduction furnished the trans 1,3-diol 5 (Scheme 2). ${ }^{5}$ The endo hydroxyl group in $\mathbf{5}$ was protected through intramolecular haloetherification to furnish tetracyclic bromoether $6^{5}$ The exo-hydroxyl group in $\mathbf{6}$ was now inverted through oxidation to ketone 7 and stereoselective reduction

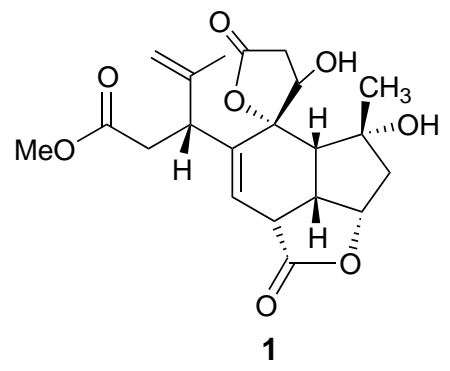

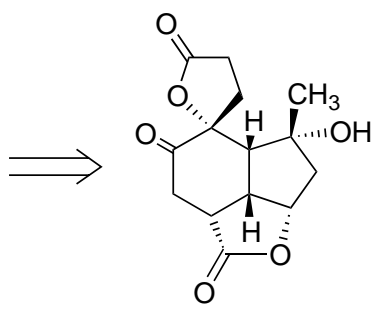

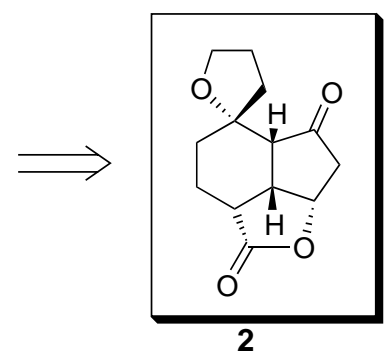

Scheme 1.

* Corresponding author. 

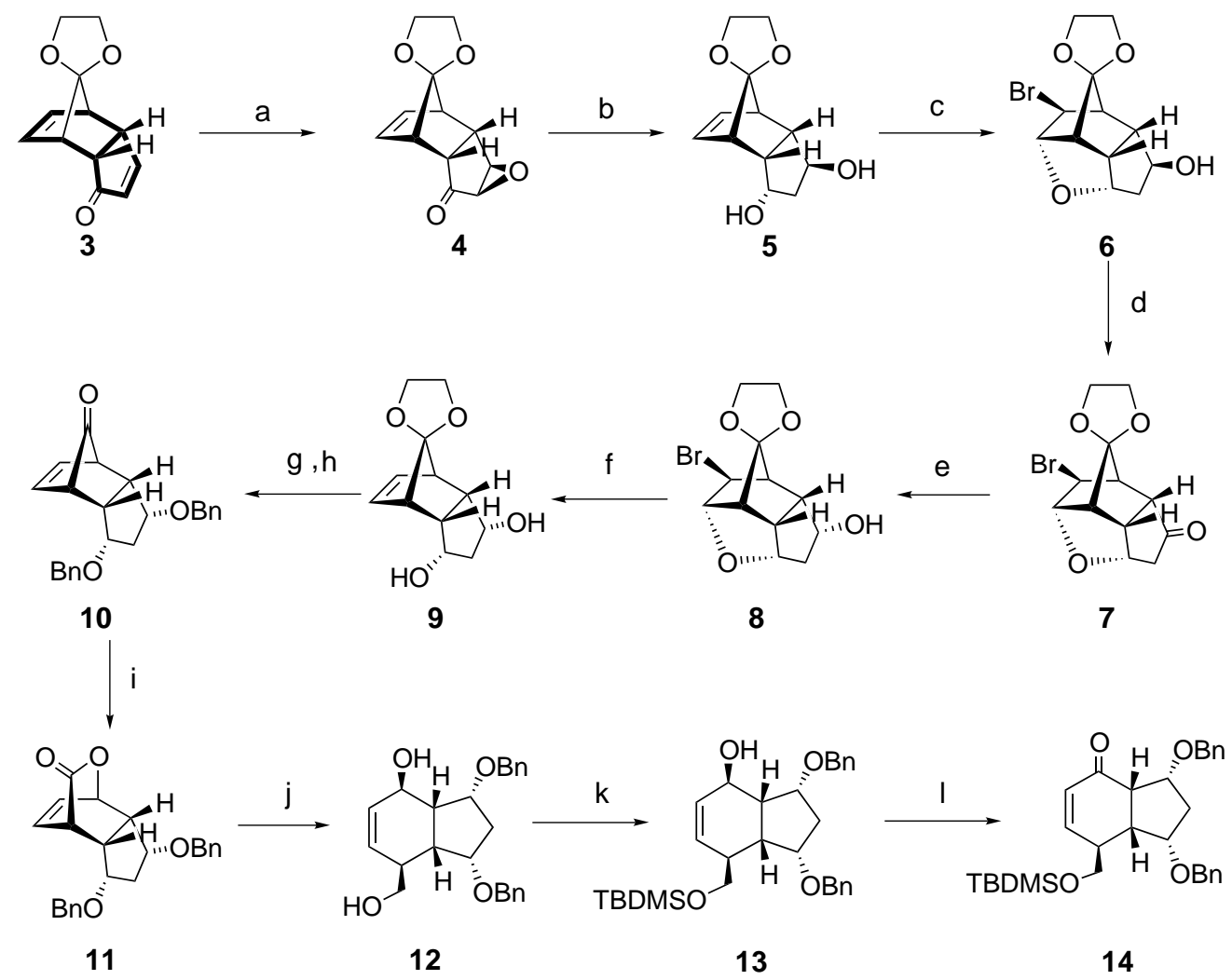

Scheme 2. Reagents and conditions: (a) $30 \% \mathrm{H}_{2} \mathrm{O}_{2}, 6 \mathrm{~N} \mathrm{NaOH}, \mathrm{MeOH}, 0^{\circ} \mathrm{C}, 30 \mathrm{~min}, 80 \%$; (b) $\mathrm{LAH}, \mathrm{THF}, 0^{\circ} \mathrm{C}$ to reflux, $4.5 \mathrm{~h}$, $88 \%$; (c) NBS, DCM, rt, 3 h, 90\%; (d) PCC, DCM, $4 \AA$ molecular sieves, $0^{\circ} \mathrm{C}$ to rt, $1 \mathrm{~h}, 85 \%$; (e) $\mathrm{NaBH}_{4}, \mathrm{MeOH}^{\circ} \mathrm{C}, 15 \mathrm{~min}$, $80 \%$; (f) $\mathrm{Zn} / \mathrm{NH}_{4} \mathrm{Cl}, \mathrm{THF} / \mathrm{H}_{2} \mathrm{O}(9: 1), 50^{\circ} \mathrm{C}, 2 \mathrm{~h}, 65 \%$; (g) $\mathrm{BnBr}, \mathrm{NaH},{ }^{n} \mathrm{Bu}_{4} \mathrm{NI}$ (cat.), $0^{\circ} \mathrm{C}$ to rt, $10 \mathrm{~h}, 72 \%$; (h) $\mathrm{Amberlyst}-15$, $\mathrm{CH}_{3} \mathrm{COCH}_{3}, 65^{\circ} \mathrm{C}, 15 \mathrm{~h}, 80 \%$; (i) $90 \%$ aq. $\mathrm{HOAc}, 30 \% \mathrm{H}_{2} \mathrm{O}_{2}, \mathrm{CH}_{3} \mathrm{COONa}, 0^{\circ} \mathrm{C}$ to rt, $6 \mathrm{~h}, 45 \%$; (j) $\mathrm{LAH}, \mathrm{THF}, 0{ }^{\circ} \mathrm{C}, 2 \mathrm{~h}, 90 \%$; (k) TBDMSCl, imidazole, DMAP (cat.), DCM, rt, 3 h, 70\%; (l) PCC, DCM, $4 \AA$ molecular sieves, $0^{\circ} \mathrm{C}$ to rt, $45 \mathrm{~min}, 89 \%$.

from the exo-face to deliver the endo-alcohol 8 (Scheme 2). ${ }^{5}$ On exposure to zinc metal, the olefinic and the hydroxyl groups could be released back from the bromoether 8 to furnish the symmetrical endo,endo-1,3-diol 9. ${ }^{5}$ Besides having the requisite stereochemistry of the hydroxyl groups, the symmetrical nature of 9 circumvented any regiochemical problems that could surface during the opening of the $\mathrm{C}-10$ bridge (vide infra). The two endo-hydroxyl groups in $\mathbf{9}$ were protected as the benzyl ethers, then ketal deprotection led to the norbornenone derivative $\mathbf{1 0}$ (Scheme 2). Carefully controlled Baeyer-Villiger oxidation on $\mathbf{1 0}$ delivered a single lactone 11, which was reductively cleaved to unravel the cis-hydrindane $\mathbf{1 2}$ with secured stereochemistry at six stereogenic centers. The primary hydroxyl group in $\mathbf{1 2}$ was selectively protected as the TBDMS-ether $\mathbf{1 3}$ and the secondary alcohol oxidized with PCC to deliver enone 14, a key substrate on which two lactone moieties present in the target compound $\mathbf{2}$ were to be installed (Scheme 2).

For the stereoselective spiro-lactone annulation at the carbonyl site in 14, a RCM based protocol was preferred. ${ }^{6}$ Addition of vinylmagnesium bromide to $\mathbf{1 4}$ occurred exclusively from the convex face to give vinyl alcohol 15 (Scheme 3). Allylation of the tertiary hydroxy group in $\mathbf{1 5}$ was smooth and the allyl-ether $\mathbf{1 6}$ was readily realized. Exposure of $\mathbf{1 6}$ to Grubbs' catalyst gave spiro-annulated dihydrofuran $\mathbf{1 7}$ in excellent yield
(Scheme 3). The spiro-fused dihydrofuran moiety in $\mathbf{1 7}$ could be further oxidized to the corresponding $\gamma$-lactone. ${ }^{7}$ The TBDMS protective group in $\mathbf{1 7}$ was now dispensed with and the resulting primary hydroxyl group was oxidized in a controlled manner to give the exo-aldehyde 18. The next task was to invert the aldehyde stereochemistry in $\mathbf{1 8}$ and for this purpose the cyclohexene double bond in it was isomerized in the presence of DBU to deliver the $\alpha, \beta$-unsaturated aldehyde 19. Catalytic hydrogenation of 19 , besides liberating the benzyl protected hydroxyl groups, also reduced the $\alpha, \beta$-unsaturated aldehyde functionality from the preferred exo-face to deliver the endo-aldehyde group, which was concomitantly captured by the appropriately positioned endo-hydroxyl group resulting in the lactol 20. PCC oxidation of $\mathbf{2 0}$ led to the target compound $\mathbf{2}$, in the process generating not only the second $\gamma$-lactone ring but also the cyclopentanone moiety required to set-up the tertiary alcohol unit present in the natural product 1.

In short, we have accomplished a synthesis of the tetracyclic core $\mathbf{2}$ present in the marine diterpenoid havellockate 1, with good regio- and stereochemical control, from a readily available dicyclopentadienone derivative 3. The overall synthetic strategy delineated here for havellockate $\mathbf{1}$ is also amenable to adaptation for the synthesis of many novel but related diterpenoid 

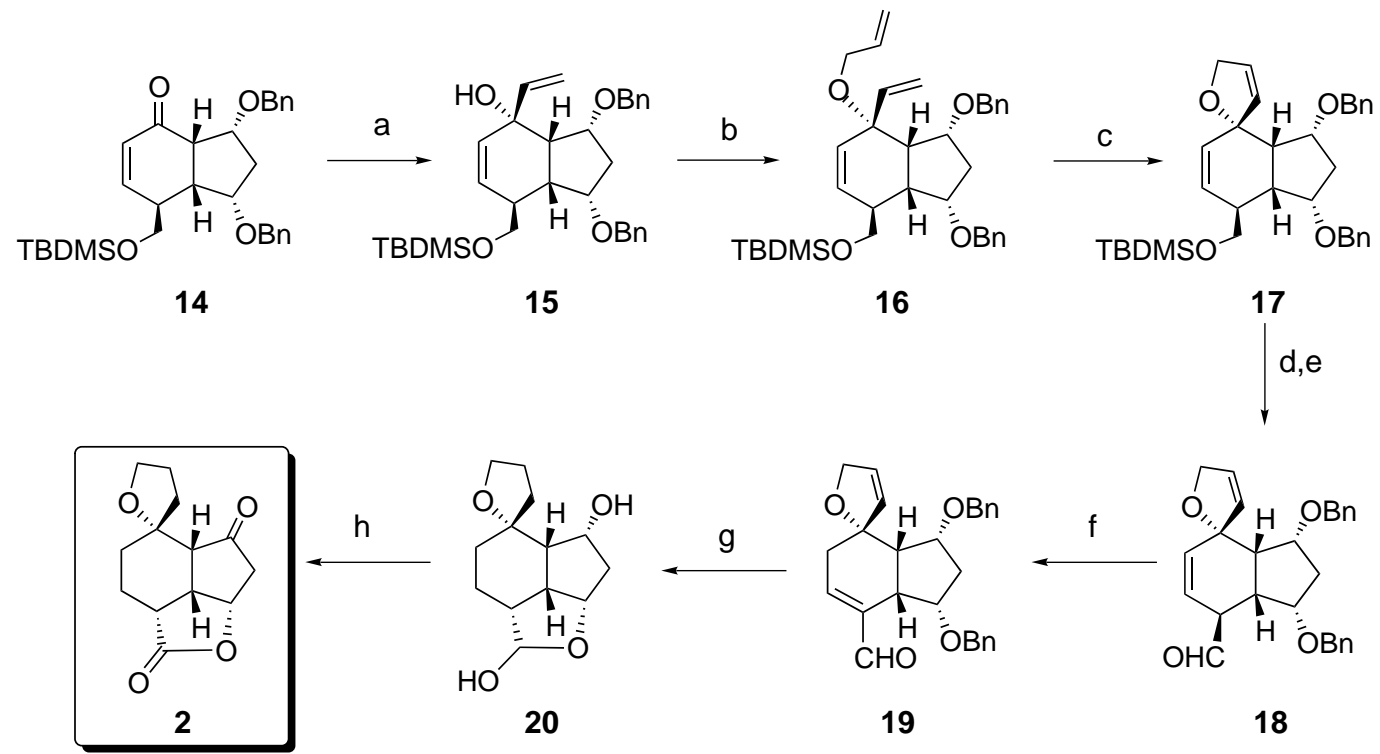

Scheme 3. Reagents and conditions: (a) vinylmagnesium bromide, $\mathrm{THF}, 0^{\circ} \mathrm{C}$ to $\mathrm{rt}, 10 \mathrm{~h}, 70 \%$; (b) allyl bromide, $\mathrm{NaH},{ }^{n} \mathrm{Bu} 4 \mathrm{NI}$ (cat.), THF, $0^{\circ} \mathrm{C}, 1$ day, 78\%; (c) Grubbs' catalyst (20 mol $\%$ ), DCM, rt, $2 \mathrm{~h} \mathrm{90 \% ;} \mathrm{(d)}{ }^{n} \mathrm{Bu}_{4} \mathrm{NF}, \mathrm{THF}, 0^{\circ} \mathrm{C}$ to rt, $10 \mathrm{~h}, 65 \%$; (e) PCC, DCM, 4 A molecular sieves, $10 \mathrm{~min}, 0^{\circ} \mathrm{C}, 70 \%$; (f) DBU, DCM, $0^{\circ} \mathrm{C}$ to $\mathrm{rt}, 1.5 \mathrm{~h}, 60 \%$; (g) $\mathrm{H}_{2}, 10 \% \mathrm{Pd}-\mathrm{C}, \mathrm{EtOAc}, \mathrm{rt}, 2 \mathrm{~h}$, $50 \%$; (h) PCC, DCM, $4 \AA$ molecular sieves, $0^{\circ} \mathrm{C}$ to $\mathrm{rt}, 15 \mathrm{~h}, 70 \%$.

skeleta of marine origin like mandapamate and isomandapamate. $^{8}$

\section{Acknowledgements}

One of us (R.S.K.) thanks CSIR for the award of a Research Fellowship. We also thank the Chemical Biology Unit of the Jawaharlal Nehru Centre for Advanced Scientific Research for research support.

\section{References}

1. Recent reviews: (a) Faulkner, D. J. Nat. Prod. Rep. 2000, 17, 7; (b) Faulkner, D. J. Nat. Prod. Rep. 1999, 16, 155 and earlier reports in this informative series; (c) Hanson, J. R. Nat. Prod. Rep. 2000, 17, 165 and earlier reports in this series.

2. Anjaneyulu, A. S. R.; Venugopal, M. J. R. V.; Sarada, P.; Clardy, J.; Lobkovsky, E. Tetrahedron Lett. 1998, 39, 139.

3. (a) Chapman, N. B.; Key, J. M.; Toyne, K. J. J. Org. Chem. 1970, 35, 3860; (b) Schuda, P. F.; Ammon, H. L.; Heimann, M. R.; Bhattachargee, S. J. Org. Chem. 1982, 47, 3434.

4. For the validation of this approach to cis-hydrindanes, see: (a) Mehta, G.; Reddy, D. S. J. Chem. Soc., Perkin Trans. 1 2001, 1153; (b) Mehta, G.; Reddy, D. S. J. Chem. Soc., Perkin Trans. 1 2000, 1399; (c) Mehta, G.; Reddy, D. S. J. Chem. Soc., Perkin Trans. 1 1998, 2125; (d) Mehta, G.; Reddy, D. S. Synlett 1997, 612; (e) Mehta, G.; Reddy, D. S. Synlett 1996, 229; (f) Mehta, G.; Praveen, M. J. Chem. Soc., Chem. Commun. 1993, 1573.
5. All new compounds reported here were racemic and characterized on the basis of spectroscopic data (IR, $v$ in $\mathrm{cm}^{-1}$, ${ }^{1} \mathrm{H}$ and ${ }^{13} \mathrm{C} \mathrm{NMR}, J$ in $\mathrm{Hz}$ ) and elemental analyses. Selected spectral data. 14: IR: 1674; $\left(300 \mathrm{MHz}, \mathrm{CDCl}_{3}\right)$ : $\delta_{\mathrm{H}} 7.37-7.18(10 \mathrm{H}, \mathrm{m}), 7.10(1 \mathrm{H}, \mathrm{dd}, J 10,2), 6.16(1 \mathrm{H}$, dd, $J 10,2.5), 4.59-4.35(4 \mathrm{H}, \mathrm{m}), 4.22-4.20(1 \mathrm{H}, \mathrm{m}), 4.09$ $(1 \mathrm{H}, \mathrm{dd}, J 9.5,3.5), 4.02-3.95(1 \mathrm{H}, \mathrm{m}), 3.61(1 \mathrm{H}, \mathrm{dd}, J 9.5$, 7.2), $2.96(1 \mathrm{H}, \mathrm{m}), 2.66-2.58(2 \mathrm{H}, \mathrm{m}), 2.48-2.38(1 \mathrm{H}, \mathrm{m})$, $1.96(1 \mathrm{H}, \mathrm{ddd}, J 14,8.5,3), 0.87(9 \mathrm{H}, \mathrm{s}), 0.00(6 \mathrm{H}, \mathrm{s}) ;(75$ $\left.\mathrm{MHz}, \mathrm{CDCl}_{3}\right): \delta_{\mathrm{C}} 198.01(\mathrm{C}=\mathrm{O}), 154.62(\mathrm{CH}), 138.40(\mathrm{C})$, $138.24(\mathrm{C}), 129.92(\mathrm{CH}), 128.38(\mathrm{CH}), 128.17(\mathrm{CH}), 127.61$ $(\mathrm{CH}), 127.36(\mathrm{CH}), 127.22(\mathrm{CH}), 127.04(\mathrm{CH}), 100.56(\mathrm{C})$, $80.93(\mathrm{CH}), 79.06(\mathrm{CH}), 72.02\left(\mathrm{CH}_{2}\right), 71.42\left(\mathrm{CH}_{2}\right), 65.28$ $\left(\mathrm{CH}_{2}\right), 51.36(\mathrm{CH}), 40.74(\mathrm{CH}), 37.82(\mathrm{CH}), 37.41\left(\mathrm{CH}_{2}\right)$, $25.87\left(\mathrm{CH}_{3}\right), 18.24(\mathrm{C}),-5.36\left(\mathrm{CH}_{3}\right)$. 17: IR: 1607; (300 $\left.\mathrm{MHz}, \mathrm{CDCl}_{3}\right): \delta_{\mathrm{H}} 7.35-7.20(10 \mathrm{H}, \mathrm{m}), 5.78-5.64(4 \mathrm{H}, \mathrm{m})$, 4.76-4.45 (6H, m), $4.00(1 \mathrm{H}, \mathrm{m}), 3.96-3.87$ (2H, m), 3.58 (1H, dd, $J$ 9.6, 6.6), 2.70-2.66 (1H, m), 2.41-2.34 (2H, m), 1.91-1.82 (2H, m), $0.88(9 \mathrm{H}, \mathrm{s}), 0.00(6 \mathrm{H}, \mathrm{s}) ;(75 \mathrm{MHz}$, $\left.\mathrm{CDCl}_{3}\right): \delta_{\mathrm{C}} 140.10(\mathrm{C}), 138.84(\mathrm{C}), 135.01(\mathrm{CH}), 130.83$ $(\mathrm{CH}), 130.37(\mathrm{CH}), 128.27(\mathrm{CH}), 127.90(\mathrm{CH}), 127.32$ $(\mathrm{CH}), 127.24(\mathrm{CH}), 126.91(\mathrm{CH}), 126.58(\mathrm{CH}), 124.11$ $(\mathrm{CH}), 88.40(\mathrm{C}), 81.59(\mathrm{CH}), 78.43(\mathrm{CH}), 74.56\left(\mathrm{CH}_{2}\right)$, $71.67\left(\mathrm{CH}_{2}\right), 71.43\left(\mathrm{CH}_{2}\right), 66.30\left(\mathrm{CH}_{2}\right), 50.09(\mathrm{CH}), 38.80$ $(\mathrm{CH}), 37.68\left(\mathrm{CH}_{2}\right), 36.62(\mathrm{CH}), 25.97\left(\mathrm{CH}_{3}\right), 18.32(\mathrm{C})$, $-5.26\left(\mathrm{CH}_{3}\right),-5.39\left(\mathrm{CH}_{3}\right)$. 19: IR: 1683, 1647; (300 MHz, $\left.\mathrm{CDCl}_{3}\right): \delta_{\mathrm{H}} 9.46(1 \mathrm{H}, \mathrm{s}), 7.28-7.20(10 \mathrm{H}, \mathrm{m}), 6.77(1 \mathrm{H}, \mathrm{m})$, 5.83-5.78 (2H, m), $4.72(2 \mathrm{H}$, br s), $4.50(2 \mathrm{H}, \mathrm{q}, J 12.5)$, 4.47-4.28 (2H, m), 4.18-4.17 (1H, m), $3.41(1 \mathrm{H}, \mathrm{t}, J 8.4)$, $3.31(1 \mathrm{H}, \mathrm{td}, J 18,3), 2.29-2.17(3 \mathrm{H}, \mathrm{m}), 1.61-1.52(2 \mathrm{H}$, $\mathrm{m}) ;\left(75 \mathrm{MHz}, \mathrm{CDCl}_{3}\right): \delta_{\mathrm{C}} 193.69,147.91,140.74,139.21$, $138.85,134.10,128.03,127.98,127.93,127.30,127.14$, $126.91,124.92,90.06,81.11,80.01,74.68,72.44,70.83$, 49.14, 40.93, 37.14, 36.73. 2: IR: 1766, 1739; (300 MHz, 
$\left.\mathrm{CDCl}_{3}\right): \delta_{\mathrm{H}} 5.08(1 \mathrm{H}, \mathrm{t}, J$ 6.6), $3.67(2 \mathrm{H}, \mathrm{m}), 3.41-3.32$ $(1 \mathrm{H}, \mathrm{m}), 2.92(1 \mathrm{H}, \mathrm{t}, J 9.9), 2.74-2.52(3 \mathrm{H}, \mathrm{m}), 2.40(1 \mathrm{H}$, d, $J 10.8), 2.35-2.24(1 \mathrm{H}, \mathrm{m}), 2.05-1.61(5 \mathrm{H}, \mathrm{m}), 1.25(1 \mathrm{H}$, td, $J 9.9,14.1) ;\left(75 \mathrm{MHz}, \mathrm{CDCl}_{3}\right): \delta_{\mathrm{C}} 216.08(\mathrm{CO}), 179.37$ (CO), $82.12(\mathrm{C}), 77.12(\mathrm{CH}), 68.35\left(\mathrm{CH}_{2}\right), 51.47(\mathrm{CH})$, $44.45\left(\mathrm{CH}_{2}\right), 38.72\left(\mathrm{CH}_{2}\right), 35.86(\mathrm{CH}), 34.15\left(\mathrm{CH}_{2}\right), 31.15$ $\left(\mathrm{CH}_{2}\right), 25.28\left(\mathrm{CH}_{2}\right), 17.45\left(\mathrm{CH}_{2}\right)$.

6. Reviews: (a) Schuster, M.; Blechert, S. Angew. Chem., Int. Ed. Engl. 1997, 36, 2036; (b) Grubbs, R. H.; Chang, H. Tetrahedron 1998, 54, 4413.

7. PCC oxidation of $\mathbf{1 7}$ readily gave the spiro fused $\alpha, \beta$ unsaturated $\gamma$-lactone (i). The double bond in (i) was suitable for the introduction of the hydroxyl group in this ring as present in the natural product $\mathbf{1}$.

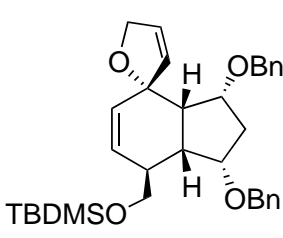

17

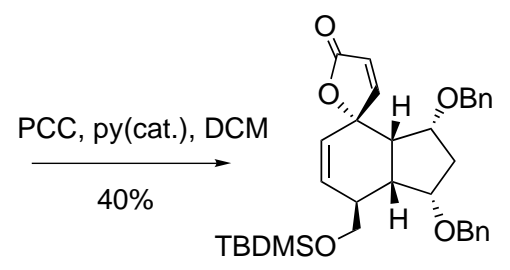

(i)
8. (a) Anjaneyulu, A. S. R.; Sagar, K. S.; Venugopal, M. J. R. V. Tetrahedron 1995, 51, 10997; (b) Venkateswarlu, Y.; Farooq Bibani, M. A.; Reddy, M. V. R.; Prabhakar Rao, T.; Kunwar, A. C.; Faulkner, D. J. Tetrahedron Lett. 1994, 35, 2249. 